\title{
Nicotinium Dichromate Oxidation of Mandelic Acid and P- Chloromandelic Acid
}

\author{
Shakuntala Mishra ${ }^{1}$, M.N. Swami ${ }^{2}$, Nagmani Manikpuri ${ }^{3}$, Arvind Prasad Dwivedi ${ }^{4}$ \\ ${ }^{I}$ Department of Chemistry, Govt. P.G. College Singrauli (M.P.) India \\ ${ }^{2}$ Department of Chemistry, R.V.P.S. Govt. College Umaria M.P. \\ ${ }^{3}$ Department of Chemistry, Govt. P.G. Nehru College Burhar, Distt. Shahdol M.P. \\ ${ }^{4}$ Department of Chemistry, Sanjay Gandhi Smrati Govt. Auto. P.G. College Sidhi M.P
}

*Corresponding Author: Shakuntala Mishra, Department of Chemistry, Govt. P.G. College Singrauli (M.P.) India

\begin{abstract}
Nicotinium dichromate (NDC) oxidation of mandelic acid and P-chloromandelic acid in aqueous acetic acid medium in presence of sulphuric acid lead to the formation of corresponding benzaldehyde and $P$-chlorobenzaldehyde as the main products. The reaction follows fractional order with respect to substrate and first-order with respect to the oxidant. Increase in percentage of acetic acid inhibited the rate of reaction. The reaction is catalysed by acid. The proposed intermediate involves a complex mechanism. The derived rate law was verified graphically. The thermodynamic and activation parameters for the oxidation have been determined and discussed.
\end{abstract}

Keywords: Nicotinium dichromate, oxidation, activation, kinetics, investigation.

\section{INTRODUCTION}

The mandelic acid and P-chloromandelic acid are bifunctional compounds contain hydroxyl $(-\mathrm{OH})$ and carboxylic group $(-\mathrm{COOH})$, exhibiting different kinds of reactions when attached by the oxidants. A lot of works on the kinetics and oxidation of mandelic acid and p-substituted mandelic acid by various oxidants like halogens, ${ }^{[1]} \mathrm{NBS}^{[2]}, \mathrm{CAB}^{[3]}, \mathrm{KMnO}_{4}{ }^{[4]} \mathrm{H}_{2} \mathrm{CrO}_{4}{ }^{[5]} \mathrm{K}_{2} \mathrm{Cr}_{2} \mathrm{O}_{7}{ }^{[6]}$, $\mathrm{NCSA}^{[7]}$ have been extensively carried out by many eminent authors.

Recently the kinetic studies on oxidation of organic compounds involving NDC are gaining wide and vast importance in alloys and leather industries due to their applications in organic synthesis and also in kinetic investigation. NDC is naturally occurring alkaloid salt of $\mathrm{Cr}(\mathrm{VI})$, has been synthesized and employed as oxidizing agents for unsaturated alcohols ${ }^{[8]}$ and uncatalyzed reaction of anilines ${ }^{[9]}$. Nicotinium chloride is usually represented by NDC. A very few reports are available of its use in kinetic oxidation studies. NDC exhibits an appreciable stability both in aqueous and non-aqueous medium in presence of an acid. Literature survey reveals that no probe on kinetic report was found on kinetics of oxidation of mandelic acid and P-chloromandelic acid by NDC.

\section{EXPERIMENTAL}

All the reagents and solvents used were of analytical grade. The solutions employed in the investigation were prepared in double distilled water. The Nicotinium dichromate was prepared using reported procedures. ${ }^{[10]}$ Its standard solution was prepared afresh before the reactions were initiated. Sulphuric acid (AnalaR) was used as sources of hydrogen ions. All the reactants were kept in a thermostated reaction vessel and the temperature was maintained at $\pm 0.1^{0} \mathrm{C}$.

The kinetic measurements were carried out in an aqueous acetic medium in presence of sulphuric acid. The reactions were performed by maintaining a large excess of [substrate] over [NDC]. The reaction rate was estimated by the amount of the unconsumed NDC iodometrically upto $80 \%$ of the completion of the reaction. The rate constants were determined from the slopes of the linear plots of $\log (\mathrm{a}-\mathrm{x})$ titre values against time for the oxidation reaction which were reproducible within $\pm 3 \%$. 


\section{RESULTS AND DISCUSSION}

The stoichiometry of the reaction was determined by installing several sets of experiments containing different quantities of NDC and substrates at constant concentration of sulphuric acid. The reactants were allowed to react for more than 24 hours at their respective experimental temperature $25^{\circ}$ and $30^{\circ}$ C.

The unconsumed NDC remained after completion of the reaction indicated 1:1 (substrate-NDC) stoichiometry. Benzaldehyde and P-chlorobenzaldehyde were found to be the major products of oxidation and were detected by their spot tests and TLC technique. It was confirmed by chemical methods and by forming their phenylhydrazones. The melting points were compared with those of the authentic samples.

The kinetics of oxidation of mandelic acid and para-chloromandelic acid have been explored at various initial concentration of oxidant (NDC) $\left(1.25-5.0 \times 10^{-3} \mathrm{~mol} \mathrm{dm}^{-3}\right)$ at fixed concentration of other reactants (Table 1). The linearity of the plots of $\log [\mathrm{NDC}]$ versus time for all indicates firstorder dependence on the reaction rate as evaluated from the slopes (Fig. 1).

The kinetic runs were performed with various initial concentrations of mandelic acid and Pchloromandelic acid which yielded rate constants. The pseudo rate constants thus obtained were found to increase with [substrate] but at higher concentration of substrate it attains optimum limiting values that declined to obey first-order kinetics and gradually values of $\mathrm{k}_{\mathrm{obs}}$ fall parallel to $\mathrm{X}$-axis showing that the reaction is fractional order in [substrate]. The study provides an intermediate evidence for the existence of complex formation between substrate and reacting species of NDC. The authors have already been reported this in their previous communication. ${ }^{[1]}$ The reaction rate constants measured with various $\left[\mathrm{H}^{+}\right]$ions were found to increase with increase in $\left[\mathrm{H}^{+}\right]$. The study shows that the reaction is catalysed by $\mathrm{H}^{+}$ion and order with respect to $\mathrm{H}^{+}$ions is unity.

The study was carried out in aqueous acetic acid mixtures of various composition (Table 2). The observed rate constant clearly revealed that the reaction velocity inhibited with increase in the percentage of acetic acid. The plots of log k vs. 1/D give rise negative intercept on X-axis (Fig.2). Addition of monomer acrylonitrile to the reaction mixture under inert nitrogen atmosphere fails to induce polymerization thus ruling out radical oxidation. The salt effect was quite neutral towards reaction rate while catalyst $\mathrm{Cu}^{++}$ions increase the rate of oxidation.

The effect of temperature was studied at four different temperatures. Various activation parameters such as energy of activation (Ea), $\Delta \mathrm{H}^{\#}, \Delta \mathrm{G}^{\#}$, and $\Delta \mathrm{S}^{\#}$ were calculated. The enthalpy and entropy of activation factors appear to be more predominating in controlling the rate of reactions.

\subsection{Mechanism}

Considering above observations and stoichiometric ratio of the reaction, the following reactions are involved to constitute the most probable mechanism of the reaction.

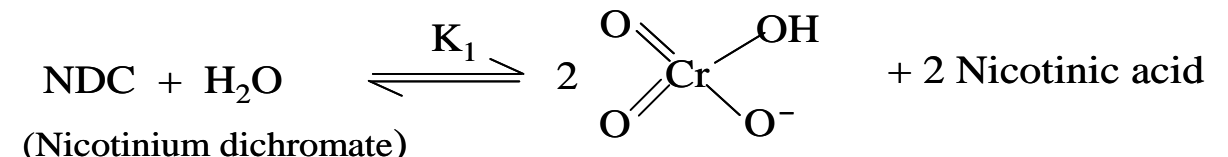

$$
\text { where } \mathrm{NDC}=
$$


<smiles>[Y4]C=C[PH3+]</smiles>

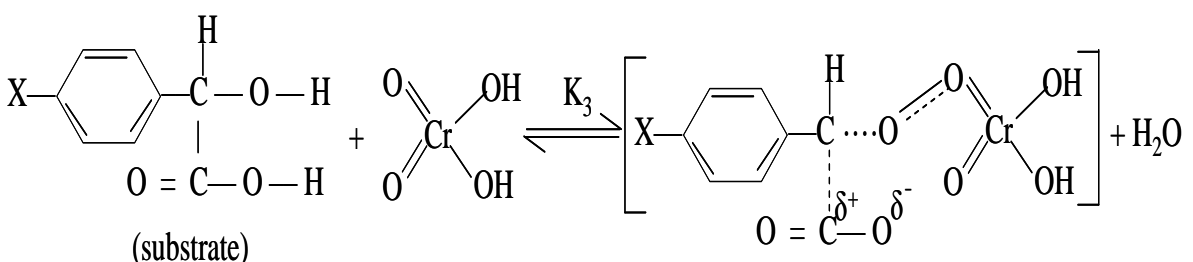

(substrate)

cyclic chromic

ester

(complex)

Where, $\mathrm{X}=-\mathrm{H}$ and $-\mathrm{Cl}$ for corresponding

Mandelic and p-chloromandelic acid

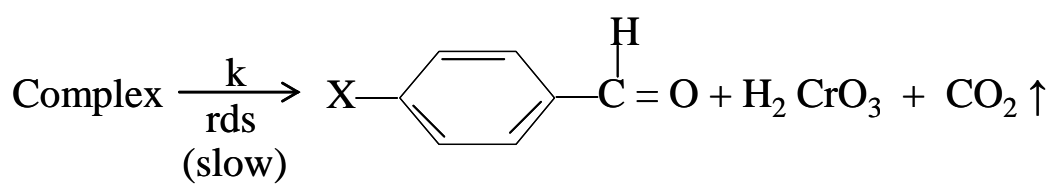

$$
\mathrm{H}_{2} \mathrm{CrO}_{3} \stackrel{\text { fast }}{\longrightarrow} 1 / 2 \mathrm{CrO}_{4}+\mathrm{H}_{2} \mathrm{O}+1 / 2 \mathrm{Cr}
$$

The rate law was finally derived

$$
\mathrm{k}_{\mathrm{obs}}=\frac{\mathrm{k} \mathrm{K}_{1} \mathrm{~K}_{3}[\mathrm{XMA}]\left[\mathrm{H}^{+}\right]}{[\text {Nicotinic acid }] \mathrm{K}_{1}+\mathrm{K}_{2}[\mathrm{H}]+\mathrm{K}_{1} \mathrm{~K}_{3}[\mathrm{XMA}]+[\mathrm{H}]}
$$

The sequence of order of reactivity was found as:

\section{$\mathrm{MA}>\mathrm{Cl} \mathrm{MA}$}

The equation (8) clearly points out the observed results as mentioned the values of activation parameters are in good consonance with the experimental results, explaining the order of reactivity. The unstable intermediate complex decomposes in a rate determining step to give the final products such as benzaldehyde and p-chlorobenzaldehyde. Over all reaction was found both enthalpy and entropy controlled

Table1. Effect of variation of [NDC] on reaction rate

$10^{2}$ [Substrate] mol dm ${ }^{3}=2.50(1), 2.0(2) ;\left[\mathrm{H}_{2} \mathrm{SO}_{4}\right] \times 10^{2} \mathrm{~mol} \mathrm{dm^{3 }}=1.0(1,2) ;$ Solvent acetic acid $=20 \%$ $(v / v)$; Temperature $K=298(1)$ and $303(2)$

\begin{tabular}{|c|c|c|c|}
\hline \multirow{2}{*}{ S. No. } & $\begin{array}{c}{[\mathrm{NDC}] \times 10^{3}} \\
\mathrm{~mol} \mathrm{dm}^{-3}\end{array}$ & \multicolumn{2}{|c|}{$\stackrel{\mathrm{k} \times 10^{4}\left(\mathrm{~s}^{-1}\right) \longrightarrow}{\longrightarrow}$} \\
\cline { 3 - 4 } & 1.25 & Mandelic acid (1) & P-Chloromandelic acid (2) \\
\hline 1. & 1.50 & 3.84 & 2.72 \\
\hline 2. & 2.00 & 3.78 & - \\
\hline 3. & 2.50 & 3.73 & 2.86 \\
\hline 4. & 3.33 & 3.75 & - \\
\hline 5. & 4.00 & 3.77 & 2.81 \\
\hline 6. & 5.00 & - & 2.78 \\
\hline 7. & 3.92 & \\
\hline
\end{tabular}

1. Mandelic acid, 2. P-Chloromandelic acid 


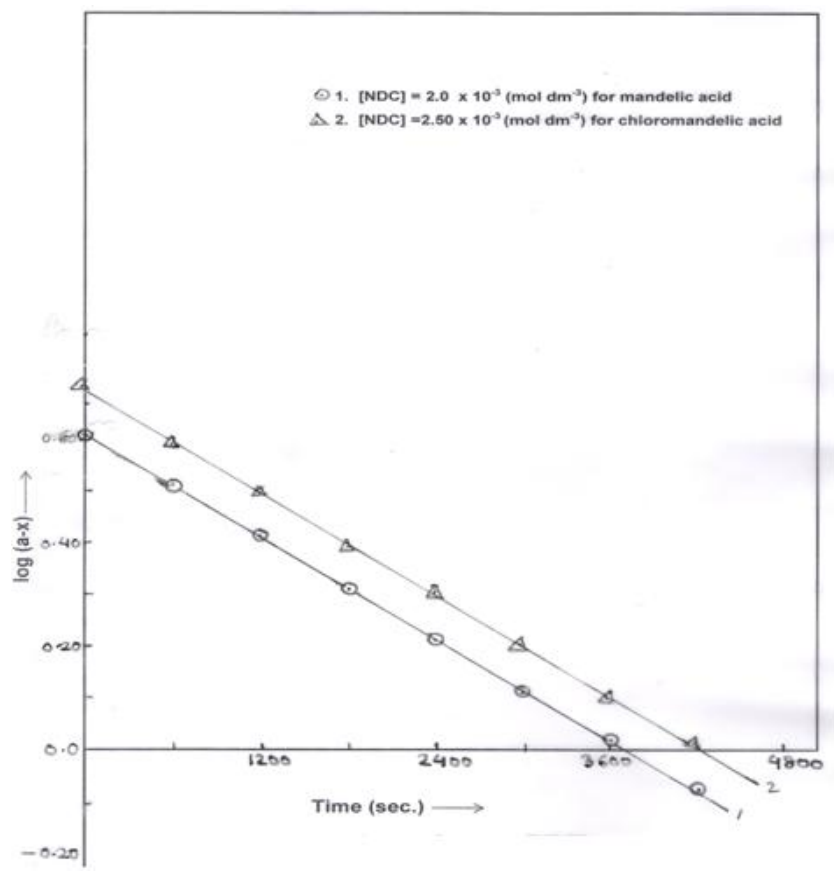

Fig1. Dependence of rate on [NDC] PLOT OF log (a-x) Vs. Time [substrate] $\times 10^{2}\left(\mathrm{~mol} \mathrm{dm}^{-3}\right)=2.50(1), 2.0$ (2); $10^{2} \times[\mathrm{H}]\left(\mathrm{mol} \mathrm{dm}^{-3}\right)=1.0(1,2) ; \mathrm{HOAc}-\mathrm{H} 2 \mathrm{O} \%(\mathrm{~V} / \mathrm{V})=20(1,2)$; Temperature $\mathrm{K}=298(1)$, 303(2)

Table2. Effect of variation of solvent composition on reaction rate

$10^{2}$ [substrate] mol dm $\mathrm{m}^{-3}=2.50(1), 2.0(2) ; 10^{3}$ [NDC] mol dm $\mathrm{m}^{-3}=2.0(1,2)$;

$10^{2} \times\left[\mathrm{H}^{+}\right] \mathrm{mol} \mathrm{dm} \mathrm{m}^{-3}=1.0(1,2)$; Temperature $K=298(1), 303$ (2)

\begin{tabular}{|c|c|c|c|c|}
\hline S. No. & $\begin{array}{c}\text { \% } \mathrm{CH}_{3} \mathrm{COOH}-\mathrm{H}_{2} \mathrm{O}, \\
(\mathrm{v} / \mathrm{v})\end{array}$ & $\frac{10^{3}}{\mathrm{D}}$ & \multicolumn{2}{|c|}{$\mathrm{k} \times 10^{4}\left(\mathrm{~s}^{-1}\right) \longrightarrow$} \\
\hline & & & Mandelic acid (1) & P-Chloromandelic acid (2) \\
\hline 1. & 10 & 15.50 & 4.13 & 3.81 \\
\hline 2. & 20 & 17.17 & 3.73 & 2.86 \\
\hline 3. & 30 & 19.15 & 2.09 & 2.48 \\
\hline 4. & 40 & 21.98 & 1.45 & 1.82 \\
\hline
\end{tabular}

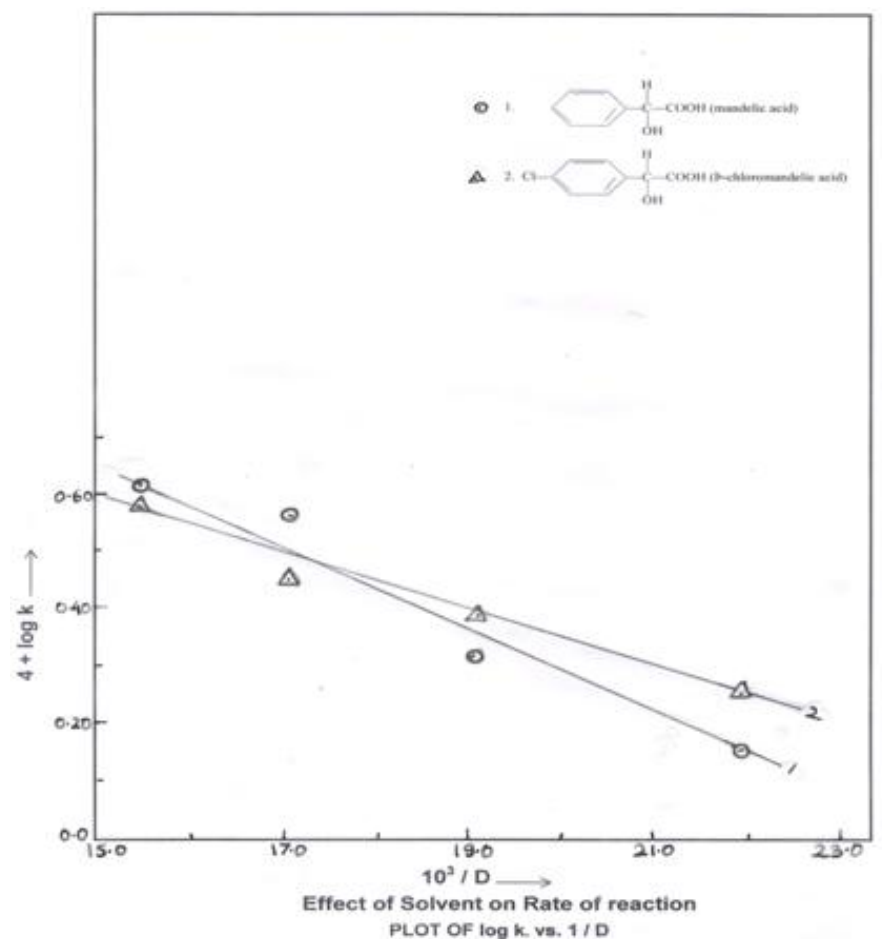

Fig2. $10^{2}\left[\right.$ Substrate] $\left(\mathrm{mol} \mathrm{dm} \mathrm{m}^{-3}\right)=2.50(1), 2.0(2) ; 10^{3}[\mathrm{NDC}]\left(\mathrm{mol} \mathrm{dm} \mathrm{m}^{-3}\right)=2.00(1,2) ; 10^{2} x\left[\mathrm{H}^{+}\right]\left(\mathrm{mol} \mathrm{dm}^{-3}\right)=$ $1.00(1,2)$; Temp. $K=298(1), 303$ (2) 


\section{CONCLUSION}

NDC has been proven to be an excellent oxidant for the oxidative study of aromatic and Phalosubstituted mandelic acids. The kinetic and thermodynamic parameters for the oxidation of MA and XMA by NDC were evaluated and the reaction mechanism was proposed. The thermodynamic data obtained supported the proposed scheme of mechanism.

\section{REFERENCES}

[1] Tapodi, H.P., Shanker, R., and Bakore, G.V., Indian J. Chem., 1980, 19, 330

[2] Bishnoi, M.L., Negi, S.C., and Banerji, K.K., Indian J. Chem., 1986, 25, 660.

[3] Mathur, A.K., Sharma, V., and Banerji, K.K., Indian J. Chem., 1988, 27, 123.

[4] Bakore, G.V., Shanker, R., and Goyal, U., Indian J. Chem., 1963, 1, 331.

[5] Sundaram, S., and Venkatasubramanian, N., Curr. Sci., 1967, 33, 646

[6] Saran, N.K., Acharya, R.C., and Rao, S.R., J. Indian Chem. Soc., 1985, 62, 747.

[7] Singh, V.P., Khan, M.U., Chauhan, D.B.S., and Verma, J.K., Oxid. Commun., 1997, 20(1), 124-131.

[8] Palanippan, A.N., Vaideki, S., ShriNivasan, S., and Raju, C., J. Chem. Pharm. Res., 4(1), 640-647, 2012.

[9] Durvas, S., Bhuraneshwani, Kuppanagounder, and Elango, K.P. J. Indian Chem. Soc., 2003, 60(b), 11051111.

[10] Mishra, Shakuntala, and Khan, M.U., Ele. J. Adv. Research, 2017, 3(2), 95-101.

[11] Soni, Mamta, Mishra, Shakuntala, and Khan, M.U., J. chemtracks, 2014, 16(1), 73-78.

Citation: S. Mishra et al., "Nicotinium Dichromate Oxidation of Mandelic Acid and P-Chloromandelic Acid", International Journal of Advanced Research in Chemical Science (IJARCS), vol. 5, no. 2, pp. 9-13, 2018. http://dx.doi.org/10.20431/2349-0403.0502003

Copyright: () 2018 Authors. This is an open-access article distributed under the terms of the Creative Commons Attribution License, which permits unrestricted use, distribution, and reproduction in any medium, provided the original author and source are credited. 